\title{
Relationship between the Level of Personal Autonomy in High School Students and the Rate of Teachers' Attention to Teaching Approaches of Personal Autonomy
}

\author{
Mohammadhossein Heydari ${ }^{1}$, Mohammadreza Neyestani ${ }^{1}$, Amir Ghamarani ${ }^{1} \&$ Salar Faramarzi ${ }^{1}$ \\ ${ }^{1}$ Department of Educational Sciences \& Psychology, University of Isfahan, Iran \\ Correspondence: Mohammadhossein Heydari, Department of Educational sciences \& Psychology, University of \\ Isfahan, Hezar jerib St., Isfahan, 81746-73441, Iran. Tel: 98-917-715-6112. E-mail: mhheidari1353@gmail.com
}

Received: January 11, 2012 Accepted: March 5, $2012 \quad$ Published: June 1, 2012

doi:10.5539/jel.v1n1p35 URL: http://dx.doi.org/10.5539/jel.v1n1p35

\begin{abstract}
The aim of this research was to study the relationship between the level of personal autonomy of students and the rate of teachers' attention to teaching approaches of personal autonomy. To this end, according to the "personal autonomy criteria" proposed by Peters and Dearden i.e., authenticity, rational reflection and strength of will and also with regard to local conditions in the region of the study; a questionnaire was constructed by the researchers to measure the level of students personal autonomy. Also according to the teaching approaches that help promoting personal autonomy, another questionnaire was constructed by the researchers to measure rate of teachers' attention to these approaches in view of same students. This study was conducted using the correlation method. The statistical population consisted of 516 graduated students from high schools of Shiraz in the year 2009 till 2010 that were chosen by using stratified randomized sampling. The results showed that there is a significant positive relationship between the level of personal autonomy in high school students and the rate of teachers' attention to teaching approaches of personal autonomy. In addition there is a significant positive relationship among the three criteria (or conditions) of personal autonomy and rate of teachers' attention to teaching approaches of personal autonomy.
\end{abstract}

Keywords: personal autonomy, personal autonomy criteria, teaching approaches

\section{Introduction}

In recent decades, personal autonomy has been considered by educators all around the world and many books and articles on its theoretical and practical aspects has been wrote. Some educational experts believe that in order to achieve ideals, such as freedom and rationality, educational systems must seek to educate independent and autonomous persons. Furthermore children need to be prepared for independent life as adults and education is one of the main routes, if not the only one, for achieving it (Winch, 1999).

In order to discuss the concept of "personal autonomy", different definitions and criteria have been proposed by educators. This paper firstly presents a brief history of personal autonomy by the emphasis on the views of two famous educational philosophers i.e., R. S. Peters and R. F. Dearden, (the educators that their criteria for personal autonomy have been used for constructing the "personal autonomy questionnaire" in this study). It is noteworthy that although many newer studies of personal autonomy has been done in different parts of the world, views of R. S. Peters and R. F. Dearden forms the foundation of subsequent studies. In second part of literature Review, a number of teaching approaches that can promote the level of personal autonomy in the learning environments are listed. Following this, the paper presents the results of studies conducted to explore and examine the proposed outcomes. Finally, the paper culminates with a discussion on the research findings and general conclusions.

\section{Literature Review}

The core idea of autonomy is that of sovereignty over oneself, self-governance or self-determination: an agent or political entity is autonomous if it is self-governing or self-determining. The ancient Greeks applied the term to city-states. City-states had autonomy if it had authority to enact its own laws and to manage its own affairs, independently of any foreign power. In the modern period, the concept was extended to persons, in particular by Kant, who gave autonomy a central place in philosophical discourse. Thus, autonomy is often understood as the 
capacity to critically assess one's basic desires and values, and to act on those that one endorses on reflection. In other contexts, autonomy is understood as a right, for example as the right to act on one's life, without interference by others (Craig, 1998).

Among the criteria that are provided for personal autonomy, Peter's criteria are more famous. R.S. Peters in one of his articles titled "freedom and the development of the free man" has mentioned three criteria for calling a person "autonomous":

\subsection{Authenticity}

Peters details his authenticity-condition of autonomy in this way:

Etymologically, "autonomy" suggests that a person accepts or makes rules for himself ... It denies that the individual's code of conduct is simply one that he has picked up from others or adopted in any second-hand way. The rules which he lives by are not just those that are laid down by custom or authority ... [T] his is represented as what the individual really wants as distinct from what conformity dictates (Peters, 1973, p. 15).

\subsection{Rational Reflection}

Peters' second condition of autonomy - associated with assessment and criticism - is a rationality-condition: "The individual is conceived of as being aware of rules as alterable conventions which structure his social life. He subjects them to reflection and criticism in the light of principles and gradually emerges with his own code of conduct" (pp. 15-16).

According to Peters, then, a person's choices are in the condition of autonomy when they fulfill the following requirements:

A choice of an agent is autonomous, if and only if,

1) The choice is under his control,

2) It is authentic, and

3) He has rationally reflected upon (the principles behind) it.

4) He reflectively reviews his decisions and behaviors.

\subsection{Strength of Will}

Peters' third condition of autonomy is Strength of will. He emphasized that: "It is possible for a person to have a code of conduct which he has worked out for himself but to be too weak-willed to stick to it. Usually, however, when people speak of a person being autonomous they mean that he not only has thought out his own code but that he is also capable of sticking to it in the face of counter inclinations".

According to these criteria, R. F. Dearden suggests seven activities or characters that mark out an autonomous person in a more obvious way:

1) Wondering and asking, with a sense of the right to ask, what the justification is for various things which it would be quite natural to take for granted;

2) Refusing agreement or compliance with what others put to him when this seems critically unacceptable;

3) Defining what he really wants, or what is really in his interests, as distinct from what may be conventionally so regarded;

4) Conceiving of goals, policies and plans of his own, and forming purposes and intentions of his own independently of any pressure to do so from others;

5) Choosing amongst alternatives in ways which could exhibit that choice as the deliberate outcome of his own ideas or purposes;

6) Forming his own opinion on a variety of topics that interest him;

7) Governing his actions and attitudes in the light of the previous sorts of activity.

Dearden adds "In short, the autonomous man has a mind of his own and acts according to it". And this 'mind of his own' will typically be no purely natural product, but the outcome of one sort of education (Dearden, 1975).

\section{Teaching Approaches of Personal Autonomy}

As noted above, Dearden (and many other educators) stipulates that personal autonomy is the outcome of one sort of education. It seems that in achieving personal autonomy as an educational aim, teachers' attitudes and performance play an important role. Teachers that emphasize excessively on values such as conformity to group 
and obedience would lead students to heteronomy. Some of suggested teaching approaches that can promote personal autonomy of students are outlined briefly as follows:

1) Avoid excessively use of punishment and encouragement in class.

2) Forming an atmosphere based on "exchange of views" in class.

3) Avoid one-way or teacher-oriented methods of teaching.

4) Encourage students to assess the views of their classmates to reinforce their own views.

5) Avoid benevolent help to students.

6) Avoid encountering to students from an upper position in scientific debates.

7) Being impartial when antagonist and challenging viewpoints is brought forth for discussion (Heydari, 2009).

\section{Related \& Similar Researches}

In obtaining the results and summaries of performed studies in Iran and other countries about the relationship between the level of personal autonomy of students and the Rate of teachers' attention to teaching approaches of personal autonomy, no research having the same subject with this study was found. So some abstracts of relatively near studies are presented here:

Nakata (2011) in his study titled "investigate teachers' readiness for promoting learner autonomy" attempted to explore the use of strategies for promoting learner autonomy among Japanese high school teachers of English as a foreign language (EFL). Results show that many Japanese EFL high school teachers, while displaying different dimensions of autonomy in different ways, are not fully ready to promote autonomy in their learners.

Drexler (2010) in a research named "The Networked Student Model for Construction of Personal Learning Environments: Balancing Teacher Control and Student Autonomy" believed that his article is meant to facilitate further discussion about K-12 student construction of personal learning environments and offer the practitioner a foundation on which to facilitate a networked learning experience. It seeks to determine how a teacher can scaffold a networked learning approach while providing a foundation on which students take more control of the learning process.

Su \& Reeve (2011) wrote in their paper titled "A Meta-Analysis of the Effectiveness of Intervention Programs Designed to Support Autonomy" that the purpose of their study was, first, to determine whether training intervention programs designed to help people support the autonomy of others are effective and, second, to identify the set of conditions that allowed these interventions to be most effective. A meta-analysis of the findings from 19 studies with 20 effect sizes showed that the training programs were, overall, effective with a weighted effect size of 0.63 . Moderator analyses of the overall effect size showed that the relatively more effective intervention programs were structured in ways that trained multiple elements of autonomy support and were presented in relatively brief $(1-3 \mathrm{~h})$ sessions in a laboratory training setting that focused on skill-based activities and utilized multiple types of media to deliver its content. Furthermore, relatively effective intervention programs were offered to teachers (rather than to other professionals), trainees (rather than to experienced professionals), and individuals with an autonomy (rather than a control) causality orientation. Though the small number of included studies warrants caution, results generally affirmed the effectiveness of autonomy-supportive training programs and identified the conditions under which future programs can be designed to be highly effective.

Robertson (2010) in her Doctoral Dissertations titled "Autonomy and Self-Determination Theory in Different Contexts: A Comparison of Middle School Science Teachers' Motivation and Instruction in China and the United States" examined factors that contribute to Chinese and United States middle school science teachers' perceptions of autonomy support. The analyses of the interviews showed that teachers in both countries reported that autonomy was important to their motivation and the quality of instruction they provided to students. Teachers from the two countries differed in their satisfaction with current levels of autonomy and reported different constraints on teaching science related to materials, lab space, curriculum standards, and assessment.

\section{Hypotheses}

H1: There is a significant relationship between level of personal autonomy in high school students and the rate of teachers' attention to teaching approaches of personal autonomy.

H2: There is a significant relationship between level of authenticity in high school students and the rate of teachers' attention to teaching approaches of personal autonomy.

H3: There is a significant relationship between level of rational reflection in high school students and the rate of 
teachers' attention to teaching approaches of personal autonomy.

H4: There is a significant relationship between level of strength of will in high school students and the rate of teachers' attention to teaching approaches of personal autonomy.

\section{Methodology}

This study was conducted using the correlation method. Correlation research method is the ability to prove a positive or negative correlation between two subjects (Dellavar, 2007). The statistical population consists of graduated students from high schools of Shiraz from the year 2009 till 2010 that were chosen by using stratified randomized sampling.

The tools for gathering data was two researcher-made questionnaires for level of personal autonomy with 18 items and rate of teachers' attention to teaching approaches of personal autonomy with 12 items based on Likert five-point scale ( $5=$ strongly agree and $1=$ strongly disagree) (Copies of the questionnaires are in the Appendix). In total, 700 questionnaires were circulated to targeted population. Out of 650 questionnaires, we received 516 completed questionnaires. This response rate is quite suitable for this type of study. By using Alpha Cronbach coefficient, reliability coefficients were obtained equal to 0.92 for first and 0.95 for second one. Also, both questionnaires were confirmed by 10 faculty members and 19 experts in the university in terms of nominal and content validity. The analysis of the data was performed in two levels of descriptive (frequency, percentage, cumulative percentage) and inferential level (correlation coefficient), using SPSS statistical software.

\section{Findings}

In order to determine the level of personal autonomy of subjects and for the ease of comparison, scores are classified in three levels: weak, average and good. The criterion for this classification was that if one of the respondents chooses "No idea $=3$ " for all 18 questions, his score will be 54; that is a weak score in researcher viewpoint, and is considered as the minimum score. Thus, scores above 54 until the maximum score that is 90 are divided to average and good levels and scores lower than 54 are considered as weak score (Table 1).

Table 1. Frequency, percentage, cumulative percentage of the total scores for personal autonomy questionnaire

\begin{tabular}{|c|c|c|c|c|c|c|c|c|c|c|c|}
\hline $\begin{array}{l}\text { cumulative } \\
\text { percentage }\end{array}$ & percentage & frequency & scores & $\begin{array}{l}\text { cumulative } \\
\text { percentage }\end{array}$ & percentage & frequency & scores & $\begin{array}{l}\text { cumulative } \\
\text { percentage }\end{array}$ & percentage & frequency & scores \\
\hline $84 / 5$ & $4 / 8$ & 25 & 65 & $16 / 3$ & $3 / 5$ & 18 & 53 & $0 / 2$ & $0 / 2$ & 1 & 38 \\
\hline $88 / 6$ & $4 / 1$ & 21 & 66 & $20 / 3$ & $4 / 1$ & 21 & 54 & $0 / 6$ & $0 / 4$ & 2 & 40 \\
\hline $90 / 9$ & $2 / 3$ & 12 & 67 & $26 / 4$ & 6 & 31 & 55 & $0 / 8$ & $0 / 2$ & 1 & 42 \\
\hline $92 / 6$ & $1 / 7$ & 9 & 68 & 31 & $4 / 7$ & 24 & 56 & 1 & $0 / 2$ & 1 & 43 \\
\hline $94 / 8$ & $2 / 1$ & 11 & 69 & $37 / 8$ & $6 / 8$ & 35 & 57 & $1 / 2$ & $0 / 2$ & 1 & 45 \\
\hline $95 / 9$ & $1 / 2$ & 6 & 70 & $45 / 2$ & $7 / 4$ & 38 & 58 & $1 / 7$ & $0 / 6$ & 3 & 46 \\
\hline $97 / 5$ & $1 / 6$ & 8 & 71 & 51 & $5 / 8$ & 30 & 59 & $2 / 7$ & 1 & 5 & 47 \\
\hline $98 / 3$ & $0 / 8$ & 4 & 72 & 55 & $4 / 1$ & 21 & 60 & $3 / 7$ & 1 & 5 & 48 \\
\hline $99 / 4$ & $1 / 2$ & 6 & 73 & $61 / 2$ & $6 / 2$ & 32 & 61 & 5 & $1 / 4$ & 7 & 49 \\
\hline $99 / 6$ & $0 / 2$ & 1 & 74 & $66 / 7$ & $5 / 4$ & 28 & 62 & $6 / 4$ & $1 / 4$ & 7 & 50 \\
\hline 100 & $0 / 4$ & 2 & 78 & $74 / 2$ & $7 / 6$ & 39 & 63 & $8 / 1$ & $1 / 7$ & 9 & 51 \\
\hline \multicolumn{4}{|c|}{ The total of frequencies $=516$} & $79 / 7$ & $5 / 4$ & 28 & 64 & $12 / 8$ & $4 / 7$ & 24 & 52 \\
\hline
\end{tabular}

Based on the above classification, frequency and percentage of scores located in these three levels is shown in Table 2. In another step of the study, each of the three criteria (or conditions) of personal autonomy, i.e., authenticity, rational reflection and strength of will have been studied alone: 
Table 2. Frequency and percentage of "personal autonomy scores" located in three levels

\begin{tabular}{ccccc}
\hline & weak & average & good & total \\
\hline frequency & 105 & 331 & 80 & 516 \\
percentage & $20 / 4$ & $64 / 1$ & $15 / 5$ & 100 \\
\hline
\end{tabular}

\subsection{Authenticity}

9 questions out of the 18 questions of personal autonomy questionnaire were assigned to measure authenticity. Here too, according to the previous process, scores are classified to three levels: weak, average and good respectively. Frequency and percentage of authenticity scores located in these three levels is shown in Table 3. For writing briefly, tables that show frequency, percentage and cumulative percentage for each of the criteria of autonomy is not mentioned.

Table 3. Frequency and percentage of "authenticity scores" located in three levels

\begin{tabular}{ccccc}
\hline & weak & average & good & total \\
\hline frequency & 82 & 391 & 43 & 516 \\
percentage & $15 / 9$ & $75 / 8$ & $8 / 3$ & 100 \\
\hline
\end{tabular}

\subsection{Rational Reflection}

5 questions out of the 18 questions of personal autonomy questionnaire were assigned to measure rational reflection. Here too, according to the previous process, scores are classified to three levels: weak, average and good respectively. Frequency and percentage of rational reflection scores located in these three levels is shown in Table 4.

Table 4. Frequency and percentage of "rational reflection scores" located in three levels

\begin{tabular}{ccccc}
\hline & weak & average & good & total \\
\hline frequency & 58 & 376 & 82 & 516 \\
percentage & $11 / 2$ & $72 / 9$ & $15 / 9$ & 100 \\
\hline
\end{tabular}

\subsection{Strength of Will}

4 questions out of the 18 questions of personal autonomy questionnaire were assigned to measure strength of will. Frequency and percentage of strength of will scores located in three levels is shown in Table 5.

Table 5. Frequency and percentage of "strength of will scores" located in three levels

\begin{tabular}{ccccc}
\hline & weak & average & good & total \\
\hline frequency & 220 & 225 & 71 & 516 \\
percentage & $42 / 6$ & $43 / 6$ & $13 / 8$ & 100 \\
\hline
\end{tabular}

Here, based on student's viewpoint (the students that answered to the first questionnaire), scores for the rate of teachers' attention to teaching approaches of personal autonomy are classified in three levels: weak, average and good according to the previous method. Analysis of the results related to all hypotheses indicated that correlation coefficient between mentioned variables were significant at the level of $\mathrm{P} \leq 0.05$. The rate of relationships between variables were between $r=0.35$ up to $r=0.65$, indicating an average and direct correlation between these variables (Tables 6- 8). 
Table 6. Frequency, percentage, cumulative percentage of the total scores for rate of teachers' attention to teaching approaches of personal autonomy questionnaire

\begin{tabular}{|c|c|c|c|c|c|c|c|c|c|c|c|}
\hline $\begin{array}{l}\text { cumulative } \\
\text { percentage }\end{array}$ & percentage & frequency & scores & $\begin{array}{l}\text { cumulative } \\
\text { percentage }\end{array}$ & percentage & frequency & scores & $\begin{array}{l}\text { cumulative } \\
\text { percentage }\end{array}$ & percentage & frequency & scores \\
\hline 16 & $3 / 1$ & $88 / 4$ & 45 & $21 / 3$ & $2 / 5$ & 13 & 33 & $0 / 2$ & $0 / 2$ & 1 & 17 \\
\hline 13 & $2 / 5$ & $90 / 9$ & 446 & $26 / 7$ & $5 / 4$ & 28 & 34 & $0 / 4$ & $0 / 2$ & 1 & 21 \\
\hline 10 & $1 / 9$ & $92 / 8$ & 47 & 32 & $5 / 2$ & 27 & 35 & $1 / 2$ & $0 / 8$ & 4 & 22 \\
\hline 15 & $2 / 9$ & $95 / 7$ & 48 & $41 / 5$ & $9 / 5$ & 49 & 36 & $1 / 9$ & $0 / 8$ & 4 & 23 \\
\hline 3 & $0 / 6$ & $96 / 3$ & 49 & $48 / 8$ & $7 / 4$ & 38 & 37 & $2 / 3$ & $0 / 4$ & 2 & 24 \\
\hline 6 & $1 / 2$ & $97 / 5$ & 50 & $54 / 5$ & $5 / 6$ & 29 & 38 & $2 / 5$ & $0 / 2$ & 1 & 25 \\
\hline 4 & $0 / 8$ & $98 / 3$ & 51 & 62 & $7 / 6$ & 39 & 39 & $4 / 1$ & $1 / 6$ & 8 & 27 \\
\hline 4 & $0 / 8$ & 99 & 52 & $70 / 7$ & $8 / 7$ & 45 & 40 & 6 & $1 / 9$ & 10 & 28 \\
\hline 3 & $0 / 6$ & $99 / 6$ & 54 & $73 / 8$ & $3 / 1$ & 16 & 41 & $7 / 6$ & $1 / 6$ & 8 & 29 \\
\hline 3 & $0 / 2$ & $99 / 8$ & 56 & $80 / 4$ & $6 / 6$ & 34 & 42 & 11 & $3 / 5$ & 18 & 30 \\
\hline 1 & $0 / 2$ & 100 & 58 & $82 / 8$ & $2 / 3$ & 12 & 43 & $14 / 7$ & $3 / 7$ & 19 & 31 \\
\hline \multicolumn{4}{|c|}{ The total of frequencies $=516$} & $85 / 3$ & $2 / 5$ & 13 & 44 & $18 / 8$ & $4 / 1$ & 21 & 32 \\
\hline
\end{tabular}

Table 7. Frequency and percentage of "rate of teachers' attention to teaching approaches of personal autonomy scores" located in three levels

\begin{tabular}{ccccc}
\hline & weak & average & good & total \\
\hline frequency & 214 & 280 & 22 & 516 \\
percentage & $41 / 5$ & $54 / 3$ & $4 / 3$ & 100 \\
\hline
\end{tabular}

Table 8. Results from correlation coefficient of personal autonomy and its criteria (or conditions) and rate of teachers' attention to teaching approaches of personal autonomy

\begin{tabular}{|c|c|c|c|c|}
\hline hypotheses & variables & frequency & $\mathbf{r}$ & Sig. \\
\hline$H 1$ & $\begin{array}{l}\text { Level of personal autonomy and } \\
\text { the rate of teachers' attention to } \\
\text { teaching approaches of personal } \\
\text { autonomy }\end{array}$ & 516 & $0 / 45$ & 0.001 \\
\hline$H 2$ & $\begin{array}{l}\text { Authenticity and the rate of } \\
\text { teachers' attention to teaching } \\
\text { approaches of personal autonomy. }\end{array}$ & 516 & $0 / 48$ & 0.001 \\
\hline$H 3$ & $\begin{array}{l}\text { Rational reflection and the rate of } \\
\text { teachers' attention to teaching } \\
\text { approaches of personal autonomy. }\end{array}$ & 516 & $0 / 42$ & 0.001 \\
\hline$H 4$ & $\begin{array}{l}\text { Strength of will and the rate of } \\
\text { teachers' attention to teaching } \\
\text { approaches of personal autonomy. }\end{array}$ & 516 & $0 / 47$ & 0.001 \\
\hline
\end{tabular}

\section{Discussion}

The information in Table 2 shows that from 516 graduated students that answered personal autonomy questionnaire, only 15/5 percent of them have placed in "good" level. Others which are nearly 85 percent generally believe that in their choosing and taking their positions, did not truly relay on their own approved criteria. Here we can say that, instead of autonomy, we see heteronomy in most of the Iranian students. It means that others opinions and confirmations are more important for them. 
Unfortunately on behalf of three criteria (or conditions) of personal autonomy, the situation is the same and the findings are not promising. For example, according to the information in Table 3 , only $8 / 3$ percent of the students were capable in "authenticity". It means that for more than 90 percent of them, accompanying with group is more important to have autonomy and independent judgment. Also about "rational reflection" criterion, according to Table 4, only 15/9 percent of the subjects strongly stressed on the role of reason as a reliable tool for managing life. But the majority of them, nearly 85 percent (of total numbers of weak and average level), had little interest to rational criteria in autonomy. The third criterion for personal autonomy is "strength of will". Table 5 shows that only 13/8 percent of the sample had sufficient seriousness on their own criteria and values. Comparing the figures in this table with the previous two tables, we noticed that a large percentage of the sample, i.e., $42 \%$, is located in the "weak" level. If we have a glance on the two other criteria i.e., authenticity and rational reflection, we see that the $15 / 9$ and $11 / 2$ of the subjects were located in the "weak" level. Thus in a comparison among three conditions or criteria of personal autonomy, it appears that participants in this study are weaker in the "strength of will" criterion.

On the other hand, the findings in Table 7 shows that from 516 of the students that answered the second questionnaire, only $4 / 3$ of subjects assessed the performance of their teacher "good" in paying attention to teaching approaches of personal autonomy. Whereas $41 / 5$ percent of subjects assessed the performance of their teacher "weak" in paying attention to teaching approaches of personal autonomy. It means that Iranian teachers aren't familiar to teaching approaches of personal autonomy or they are unaware of its importance of them.

The analysis of results from the first hypothesis showed that the correlation coefficient was significant between level of personal autonomy and the rate of teachers' attention to teaching approaches of personal autonomy at $\mathrm{P} \leq$ 0.05 . The rate of correlation between two variables was equal to $r=0 / 45$, indicating the linear correlation between these two variables.

The analysis of results from the second, third and fourth hypothesis showed that the correlation coefficient was significant between three criteria (or conditions) of personal autonomy and the Rate of teachers' attention to teaching approaches of personal autonomy at $\mathrm{P} \leq 0.05$ (Table 8 ). In this research, by means of Correlation method, the presence of relationship between personal autonomy and the Rate of teachers' attention to teaching approaches of personal autonomy was proved. It is clear that the causality (one factor is responsible for another factor) can be checked by means of mixed methods approach in further researches.

\section{Conclusion}

A consideration to Formal Educational Aims of Islamic republic of Iran shows that there is an emphasis on "Personal autonomy" as an important educational aim (Heydari, 2009). After nearly twenty years since the approval and implementation of these aims in Iran, the findings of this research indicate that the situation of personal autonomy in Iranian high school students isn't satisfactory. Although personal autonomy is a cognitive ability that is influenced by different social and cultural conditions, probably one of the reasons for this unsatisfactory situation can be teachers' carelessness to teaching approaches of personal autonomy. However, the causality of this relationship and other reasons and roots of this situation should be distinguished in further researches.

\section{References}

Craig, Edward (1998). Autonomy. In E. Craig (Ed.), Routledge Encyclopedia of Philosophy. London: Routledge.

Dearden, R. F. (1975). Autonomy as an Educational Ideal. In Brown, S.C. (Ed.), Philosophers Discuss Education. London: Macmillan.

Dellavar, A. (2007). Research foundations in behavioral sciences. Tehran: publication of Doran.

Drexler, Wendy. (2010). The Networked Student Model for Construction of Personal Learning Environments: Balancing Teacher Control and Student Autonomy. Australasian Journal of Educational Technology, 26(3), 369-385.

Heydari, Mohammadhossein. (2009). Personal Autonomy as an educational aim and study its backgrounds and place in Iranian Education. Ph.D. Dissertation, Shahid Chamran University, Iran.

Nakata, Yoshiyuki. (2011). Investigate teachers' readiness for promoting learner autonomy. Teaching and Teacher Education: An International Journal of Research and Studies, 27(5). 900-910. Retrieved from http://search.proquest.com/docview/878116583?accountid=27639

Peters, R. S. (1973). Freedom and the Development of the Free Man. In P. H.Hirst \& P.White (Eds.), Philosophy of Education, Major Themes in the Analytic Tradition. (pp. 11-31, Volume II). Education and Human Being, 
London, Routledge.

Reeve, Johnmarshall. (2011). A Meta-Analysis of the Effectiveness of Intervention Programs Designed to Support Autonomy. Educational Psychology Review, 23(1), 159-188. http://dx.doi.org/10.1007/s10648-010-9142-7

Robertson, Laura Elizabeth. (2010). Autonomy and Self-Determination Theory in Different Contexts: A Comparison of Middle School Science Teachers' Motivation and Instruction in China and the United States. Ph.D. Dissertation, North Carolina State University.

Winch, C. (1999). Autonomy as an Educational Aim. London: Routledge. 